\section{Leishmaniasis presenting as small isolated media- stinal lymphadenopathy diagnosed by endoscopic ultrasound-guided fine-needle aspiration}
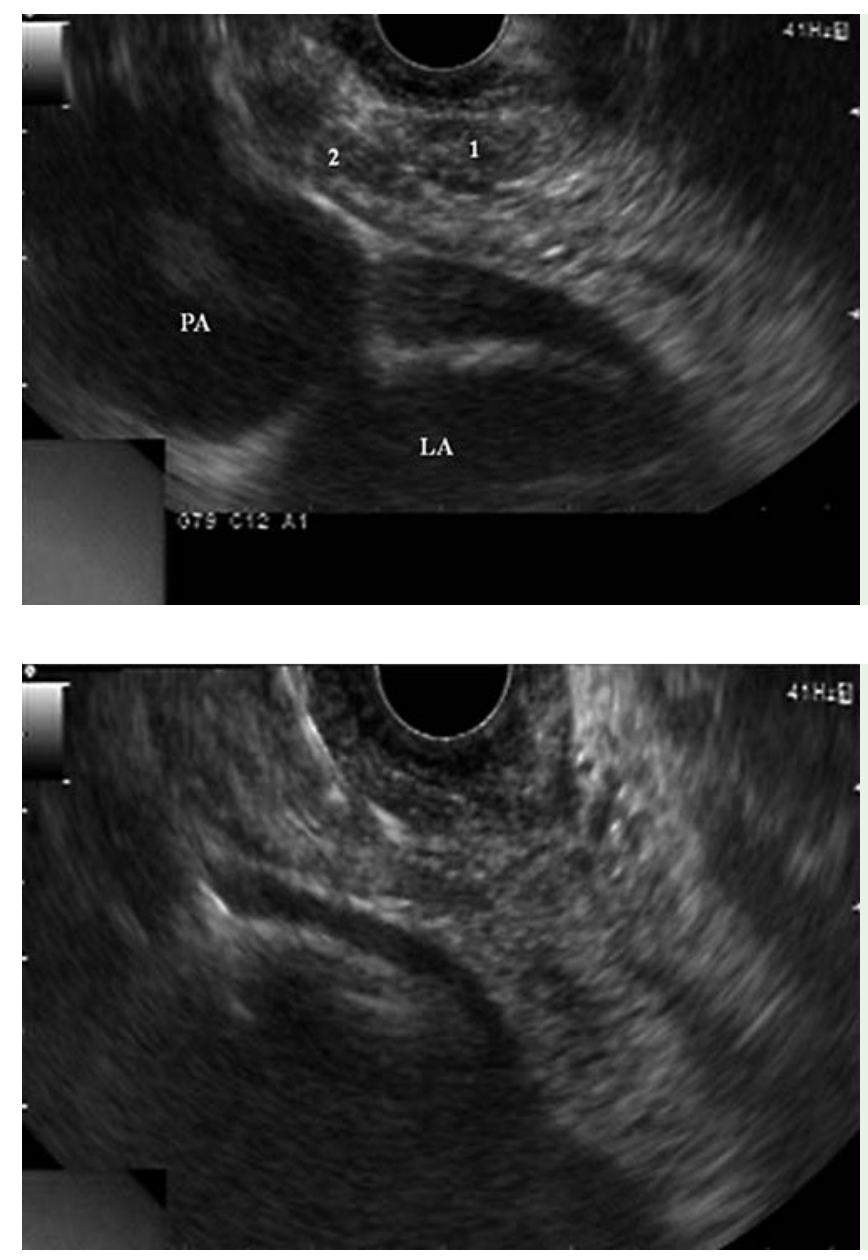

Fig. 1 Endoscopic ultrasound image showing two small lymph nodes at the subcarinal window (labeled as 1 and 2). LA, left atrium; $\mathrm{PA}$, pulmonary artery.

Fig. 2 Endoscopic ultrasound image showing needle inside lymph node (fine-needle aspiration procedure).

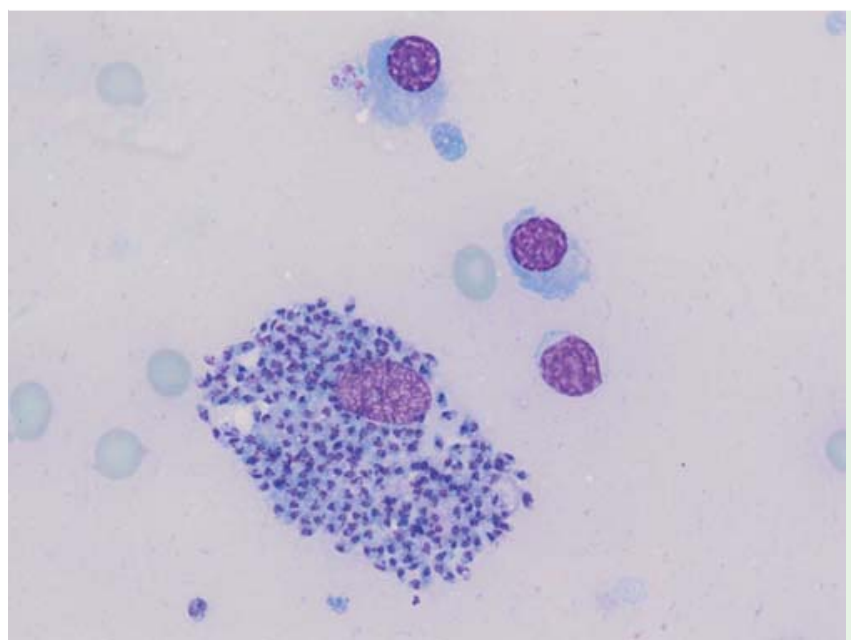

A 41-year-old man from Afghanistan presented with pyrexia of unknown origin and weight loss for 2 months. His work-up revealed anemia (hemoglobin $7.7 \mathrm{~g} / \mathrm{dL}$ ) and leukopenia (2990 cells/ $\mu \mathrm{L})$, and he was positive for human immunodeficiency virus type 1 (HIV 1).

A contrast-enhanced computed tomography of the chest and abdomen was performed, and showed small mediastinal lymph nodes with normal abdominal imaging. Endoscopic ultrasound (EUS) of the mediastinal nodes showed a few small nodes at the subcarinal window, the largest of which measured $1.2 \times 0.6 \mathrm{~cm}$. These lymph nodes had defined borders, were triangular in shape, and some had a hyperechoic center suggestive of reactive change ( $\bullet$ Fig. $\mathbf{1})$. Fine-needle aspiration (FNA) of a larger lymph node ( $\bullet$ Fig. 2) was performed because the patient did not want to undergo bone marrow examination. One needle pass with suction was made using an EchoTip 22-gauge needle (Wilson-cook Medical, Winston-Salem, North Carolina, United States). Cytopathology of the lymph node revealed numerous Leishmania donovani bodies inside and outside histiocytes ( $\bullet$ Fig. 3). The patient was offered amphotericin B treatment, but preferred to receive treatment in his home country due to financial difficulties.

This case illustrates the safety of performing EUS-FNA of small lymph nodes in the mediastinum where numerous vascular structures are located, and the importance of obtaining a tissue diagnosis even from small lymph nodes if it is indicated (the present case had pyrexia of unknown origin and immunocompromised status). Autopsy studies of the mediastinum have shown that lymph nodes that are up to $1 \mathrm{~cm}$ in the short axis are reactive in nature $[1,2]$. The present case also demonstrates the limitation of morphological EUS criteria for differentiating between reactive and pathological lymph nodes.

The Leishmania parasite can be isolated from bone marrow, spleen, liver, and lymph nodes. Leishmaniasis in HIV-positive patients may present atypically, as in the present case in which no organomegaly was seen [3]. Leishmaniasis presenting as isolated lymphadenitis is rare and should be included in the differential diagnosis in immunocompromised patients $[3,4]$. 


\section{Endoscopy_UCTN_Code_CCL_1AF_2AC}

Competing interests: None

\section{Narendra S. Choudhary', Sushila Kataria ${ }^{2}$, Mridula Guleria ${ }^{3}$, Rajesh Puri ${ }^{1}$}

${ }^{1}$ Institute of Digestive and Hepatobiliary Sciences, Medanta, The Medicity, Gurgaon, India

2 Department of Internal Medicine, Medanta, The Medicity, Gurgaon, India

${ }^{3}$ Department of Cytopathology, Medanta, The Medicity, Gurgaon, India

\section{References}

1 Kiyono $K$, Sone S, Sakai $F$ et al. The number and size of normal mediastinal lymph nodes: a postmortem study. AJR Am J Roentgenol 1988; 150: 771 - 776

2 Ziyade S, Pinarbasili NB, Ziyade $N$ et al. Determination of standard number, size and weight of mediastinal lymph nodes in postmortem examinations: reflection on lung cancer surgery. J Cardiothorac Surg 2013; 8: 94

3 Singh S. New developments in diagnosis of leishmaniasis. Indian J Med Res 2006; 123: 311-330

4 Beljan R, Sundov D, Luksić B et al. Diagnosis of visceral leishmaniasis by fine needle aspiration cytology of an isolated cervical lymph node: case report. Coll Antropol 2010; 34: 237-239

\section{Bibliography}

Dol http://dx.doi.org/

10.1055/s-0034-1377430

Endoscopy 2015; 47: E147-E148

(c) Georg Thieme Verlag KG

Stuttgart · New York

ISSN 0013-726X

\section{Corresponding author}

\section{Rajesh Puri, MD}

Institute of Digestive and Hepatobiliary Sciences Medanta

The Medicity, sector 38

Gurgaon

Haryana, PIN 122001

India

Fax: +91-124-4834111

purirajesh69@gmail.com 